\title{
Cloud computing and public administration: approaches in several European countries
}

\author{
Adrian-Mihai ZAHARIA-RĂDULESCU \\ The Bucharest University of Economic Studies, Bucharest, Romania \\ mihai.zaharia@gmail.com \\ Ioan RADU \\ The Bucharest University of Economic Studies, Bucharest, Romania
}

\begin{abstract}
The Digital Agenda for Europe 2020 has more objectives from increasing the participation of its citizens and consumers in the digital society to creating a fully interconnected society. These objectives can be supported through a high degree of digitization achieved at public administration level and an increased performance in delivering public services. Cloud computing is one of the ICT areas with a fast growth in the last years that presents a big promise for achieving the objectives of the Digital Agenda for Europe 2020. This paper aims to present what cloud computing is and how it can help the public administration to increase its performance. From Infrastructure as a Service continuing with Platform as a Service and moving up to Software as a Service each level of cloud computing is presented in here with its strong and weak points and how it is suitable for a given use case in public administration. The challenges and the risks of moving to cloud and the differences between public, private and hybrid cloud are also presented in the paper. The research done by the author is both theoretical and literature review and combines knowledge from different areas. An analysis and examples of cloud computing approach and implementation in several European Union countries are presented in this paper to facilitate the understanding of the subject. Cloud computing can help public administration to decrease costs, standardize services in different locations, integrate public resources and provide a higher transparency in the government act.
\end{abstract}

Keywords: cloud computing, public administration, performance management.

\section{Introduction}

Technology is enabling public and private organizations to achieve a higher performance and perform operations that were not possible earlier. In this context cloud computing has its stake. The transition from legacy IT systems to cloud computing is a complex process so it might be useful to start with some time flags to understand where we are today. Cloud computing has its beginning in 1950 (Destefani Neto, 2014) when the mainframe computing has arrived. Mainframe computing has allowed shared access to multiple users as the price of the technology was very high. "Around 1970, the concept of virtual machines (VMs) was created" (Destefani Neto, 2014) making possible for multiple guest operating systems (VMs) to run on a host operating systems. "In the 1990s, telecommunications companies started offering virtualized private network connections" (Destefani Neto, 2014).

In 1997, Professor Ramnath Chellapa of Emory University and the University of South California defined cloud computing as the new "computing paradigm where the boundaries of computing will be determined by economic rationale rather than technical limits alone" (Chellappa, 1997). 
According to NIST "Cloud computing is a model for enabling ubiquitous, convenient, on-demand network access to a shared pool of configurable computing resources (e.g., networks, servers, storage, applications, and services) that can be rapidly provisioned and released with minimal management effort or service provider interaction" (National Institute of Standards and Technology, U.S. Department of Commerce, 2011). The NIST cloud model is composed of five essential characteristics, three service models, and four deployment models.

According to IBM cloud computing "is a pay-per-use consumption and delivery model that enables real-time delivery of configurable computing resources (for example networks, servers, storage, applications, services). Typically, these are highly scalable resources delivered over the Internet to multiple companies, which pay only for what they use" (IBM Institute for Business Value, 2012).

\section{The characteristics of cloud}

According to NIST the essential characteristics of cloud are on-demand self-service, broad network access, resource pooling, rapid elasticity and measured service.

On-demand self-service - means that one can provision cloud capabilities (be it storage, processing time, network capacity) without any interaction with a human operator.

Broad network access - means that the access and the usage of the cloud capabilities is available via standardized network connections from different types of terminals (PCs, tablets, smartphones).

Resource pooling - means that the customer does not know the exact location of the resources and that should not matter to him as the important thing is that the proper and requested resources are made available in the shortest time and depending on the type of resource in the nearest location.

Rapid elasticity - means that the capabilities provided through the cloud service can be easily scaled up and down from the customer perspective without prior notice given by the customer to the cloud service provider when willing to achieve a growth or decrease in cloud computing capabilities.

Measured service - means that all the cloud capabilities provided to the customers can be transparently and automatically measured and reported.

\section{Cloud service models}

The service models are Infrastructure as a Service (IaaS), Platform as a Service (PaaS) and Software as a Service and can be presented like a stack (Figure 1) due to their characteristics presented in the following paragraphs. 


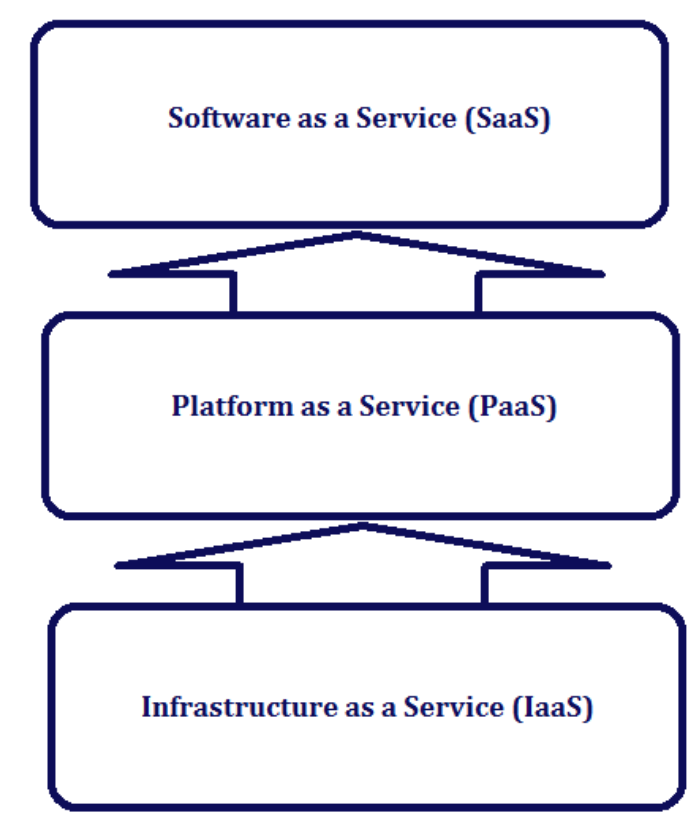

PICBE | 741

Figure 1.Cloud service models

Source: Authors' own research.

In the Infrastructure as a Service (IaaS) model the customer has access and can provision compute power, storage capacity and network capabilities in a specific manner without the need to worry about the servers' hardware as shown in Figure 2.

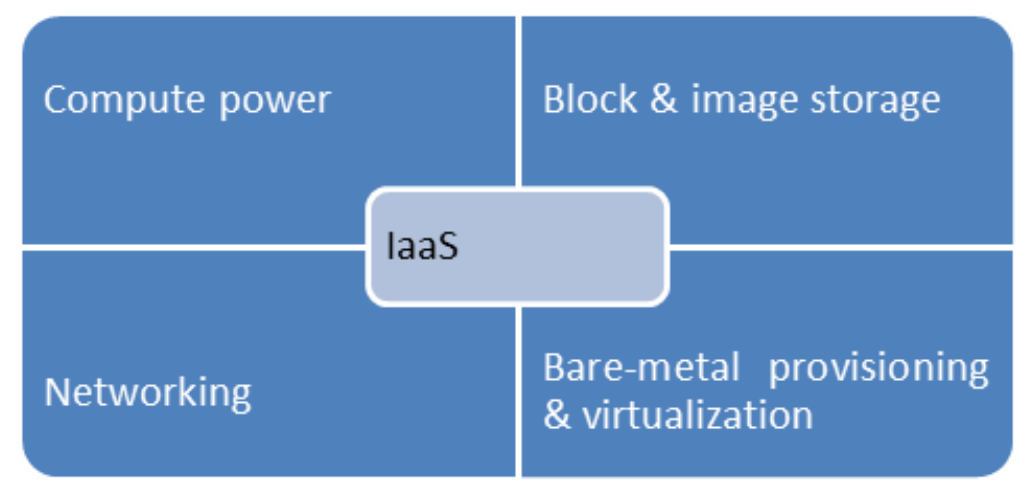

Figure 2.IaaS architecture

Source: Authors' own research.

The cloud provider will manage the hardware layer and provide the customer with access to a service from where one can deploy virtual machines and applications on the available pool of resources. As it is a cloud model the up and down scaling of the pool of resources, the hardware maintenance is transparent for the customer and it's the sole responsibility of the cloud provider. The virtual machines deployed by the customer can be built from scratch considering specific hardware configurations or can be configuration changes on standard images provided by the cloud provider. The price should not include upfront or termination costs and can be computed depending on the compute usage per hour, storage per gigabyte and more.

Google Compute Engine, Windows Azure with its virtual machines service and Amazon through CloudFormation are some of the IaaS cloud providers. 
In the Platform as a Service (PaaS) model the customer has access and can provision software components and services so that it can build new applications and services for the end user (Figure 3).

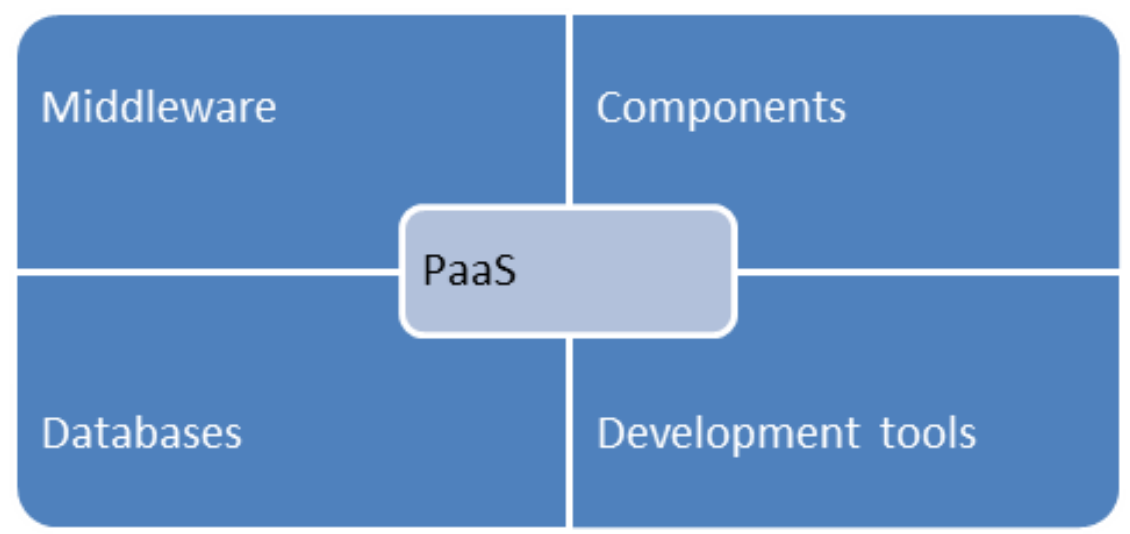

PICBE | 742

Figure 3.PaaS architecture

Source: Authors' own research.

It's a model designed for software development and vendors not willing to buy a large volume of hardware and infrastructure services from first day of writing a new application. It is also a good model for deploying new application and services without the hassle of owning and managing an entire infrastructure but strictly focus on application administration. The cloud provider will manage the hardware layer, the operating system layer and will provide the customer with access to specific database, middleware and development tools. The customer will configure one or more development repositories, a build system and the needed integrations. As in the IaaS model the price should not include upfront or termination costs and in this case can be computed depending on the number of instances of components and services used, their availability and their load. Additional services like backup or load balancing can add an extra cost for the customer. In the PaaS market Google is present with Google App Engine, Microsoft with Windows Azure Compute and Amazon with Amazon Elastic Beanstalk.

In the Software as a Service (SaaS) model the customer has access and can provision a specific number of users or other identifier of usage to a specific application or business services one wants to use (Figure 4).

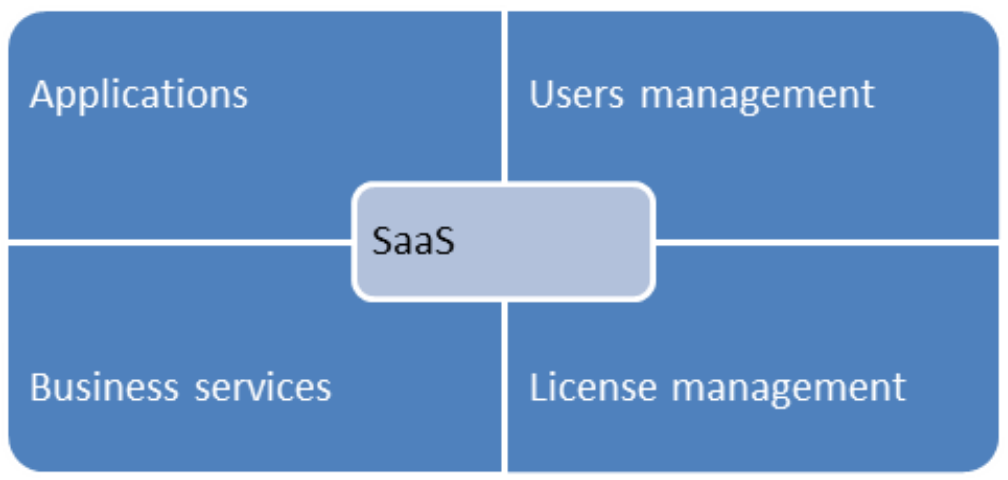

Figure 4.SaaS architecture

Source: Authors' own research. 
It's a model designed for all customers with no need to manage hardware, to write code or deploy applications. The cloud provider manages the infrastructure level, develops, deploys and maintains the applications that are provided for use to the customers. In some cases the cloud provider might use a third party for the IaaS or PaaS layer. The price should not include upfront or termination costs and can be computed depending on the number of users that are using the applications or business services. Depending on the level of service prebuilt package of services can be in place. Salesforce, Google Apps and Microsoft Office 365 are examples of SaaS offerings.

Even though there are multiple models of pricing the pay-as-you-go, the subscription model and pay-for-resources are the common approaches for cloud services. The first one makes the price transparent for the customer, does not take into consideration fluctuations of demand on the cloud provider side nor a lower usage from customer side. The second one is a fixed price for a given time interval, known in advance by the customer that does not take into consideration if the customer is using less than the provisioned capacity during that time nor that the cloud provider has higher costs if the customer is using more than the average. Pay-for-resources is setting price based on used resources which makes it

a better model, still harder to implement in practice as both the granularity in controlling and automating cloud services and the precision in setting and updating a base price for each unit of service may it be compute usage, storage blocks must be higher.

\section{Cloud deployment models}

The cloud deployment models are public cloud, private cloud and hybrid cloud.

Public cloud is a cloud that one can connect to via Internet connectivity with the hardware resources shared across all customers, useful for non-sensitive data and general operations. The advantages are that the customer can benefits from the economies of scale based on the real needs of the moment.

The private cloud is the cloud where the pool of the resources is dedicated to a certain customer and suitable for managing sensitive data and running business critical operations. A clear forecast and provision of resources must be made and the price of the service will be higher. In the private cloud scenario he maintenance and upgrade of the cloud is supported by a single customer thus making it an option for corporations or public administration rather than small businesses.

The hybrid cloud would combine the two deployment models trying to use the best of the 2 worlds where sensitive data can be stored and processed in the private area and general operations are available through the public service.

The typical challenges when moving to cloud are related to:

- security \& privacy - by that meaning if the customer data is safe from threats, the data resides on a proper storage, there are policies in place, encryption might be involved;

- service quality - as it's not an in-house solution where the customer cannot rely on its own staff how is this going to impact the performance of the service, how the cloud provider will make that any problem will be solved as soon as possible and mitigation plans will be in place;

- accessibility - important in the public cloud model as the dependency of the cloud can let the organization perform or simply perish. 
As it can be observed from the service and deployment models the benefits are:

- no up-front expenses - the organizations do not need to procure infrastructure prior the transition to cloud;

- easier access - in most cases the access is over the Internet;

- lower operational costs - the pay-as-you-go model let the organizations manage their costs better;

- scalability - cloud providers manage the up and down scaling using the large pool of owned resources this way reducing the hassle of the organization with procurement, configuration, deployment of new configuration items.

\section{Digital Agenda for Europe}

The Digital Agenda for Europe is one of "the seven flagship initiatives of the Europe 2020 Strategy" (European Commission, 2010) launched by the European Commision in March 2010. The scope of the Europe 2020 Strategy is to "exit the crisis and prepare the EU economy for the challenges of the next decade". The expectations of the agenda are to "maximize the social and economic potential of ICT, most notably the Internet, a vital medium of economic and societal activity". According to the same document "Europe makes little use of procurement of innovation and $R \& D$ to improve quality and performance of its public services" and one of the methods to achieve this is through a European strategy related to cloud computing for government and public services.

Cloud computing can facilitate the share of information between public and private organizations and provide citizens access to government services. An IDC study (Tweneboah-Koduah et al., 2014) states that "the worldwide spending on public cloud services reached $\$ 47.4$ billion in 2013 and is expected to be more than $\$ 107$ billion in 2017".

Acting by specific laws, public policies and programs make the transition slower for public organizations. Data security and privacy are the major concerns for public organizations as the Government needs to comply with the legislation and has the duty to protect its citizens. More than that Government needs to know that data is stored and processed under the terms of government legal and territorial jurisdiction and audit that continuously. Loss of data or not being sure that data is processed accordingly to the public policy can be a threat to sovereignty and lead to a lack of trust from the citizens as well. There should be no case when data is lost as for the typical business, citizens and government data cannot be covered by an insurance company. There is also classified information that cannot be stored into a public cloud.

Lack of a reliable and stable Internet connectivity and infrastructure can be another factor in a slow transition to cloud services for the public administration. A population with a limited broadband access and with low digital skills will not embrace easily public administration services offered in the cloud.

Interoperability and the use of open standards is imperative for cloud adoption by public administration to avoid vendor lock-in that would lead to lost trust from citizens side, additional costs and effort if migration to another cloud service is needed.

The European Commission has launched in 2012 a cloud strategy subtitled "Unleashing the Potential of Cloud Computing in Europe" (European Commission, 2012) and the European Union Agency for Network and Information Security has published a 
step-by-step guide for member states to help in the processes of procuring and using cloud services.

\section{How cloud adoption looks in different EU states}

It is not in the purpose of this paper to present the adoption rate in private organizations across Europe, nor to present success stories related to cloud computing in private European sector, but to focus only on presenting cloud computing adoption in public European organizations.

In The Netherlands the national legislation has been aligned to the European one. The government has its private cloud with consolidated data centers as in 2013 and 2014 66 data centers have been merged into four (Draoli, 2014). Rijks Application Store (RAS) is hosted in this cloud providing "e-infrastructure for the public servant" (EAR Online). RAS has been launched on 1st of July, 2014 and its' design is similar to any other known application store.

In Romania the Ministry for Information Society (MIS) is the authority that manages the implementation of the Digital Agenda for Europe. The level of cloud adoption across business and public sector is not very much different. A national network providing interconnection between local and central administration management information systems is underway. The biggest progress is related to the national legislation that has been aligned to the European one. Public services are not integrated into a single catalogue of services as multiple public entities are responsible for their development and databases of different institutions are not linked. However it is worth mentioning there are several projects that lead in the e-government program: the eGovernment portal that wants to be a one-stop-shop to central and local public services (European Commission, 2015), the National eProcurement system for whom the Agency for Digital Agenda is responsible and the Virtual Payment Office.

In Portugal the government is committed to decrease ICT costs in public administration (Draoli, 2014). Entities in the public sector had their own applications, services and infrastructure making it hard for the government to create an infrastructure that is highly operable, easy to manage where new services can be added and data can be shared across different public sector entities. This context lead to the GO-Cloud initiative willing to provide a shared infrastructure and services designed for integration and standardization.

In Slovakia the authority responsible with the Digital Agenda is the Ministry of Finance. An Information Society Division acts on behalf of the Ministry in regard to egovernment and issuing standards for information systems to be used in public administration. The national legislation is aligned with the European one favoring the progress on the Digital Agenda. The National Agency for Networking and Electronic Services is the authority assigned to manage and develop the government data network and the public administration portal. The public administration portal provides more than 800 eGovernment services (European Commision, 2016) for both businesses and citizens. The Government has designed and approved a cloud strategy in 2014 aiming to provide cloud services to all public administration institutions.

Based on the government strategy the Data Center of Municipalities project (DCOM) has been developed and was even nominated in the category Best Cloud Service for Vertical Markets during the EuroCloud Country Awards in 2015 (European Commission, 2016). This 
project will serve more than 2900 municipalities (Draoli, 2014) integrating multiple registers (Register of natural persons, Register of legal entities, Cadaster, Register of addresses) and already existing management information systems used by public institutions. The services are delivered via the SaaS model. The Point of Single Contact portal provides to business owners services related to the Trade register. One of the points of the strategy for 2014-2020 is to consolidate the state data centers into 2 data centers that will provide all public administration institutions with all cloud service models (IaaS, PaaS, SaaS) through a catalogue of services.

In Spain the Ministry of Finance and Public Administration is authority responsible with the migration of public services into cloud and the legislation is aligned to the European one. The public administration ICT is connected via Red SARA (the Telecommunication Network of the Spanish Public Administration). SARA provides interconnectivity between public administration entities and connectivity with European Union institutions and represents the foundation of Spain's public administration private cloud. Under the Ministry of Finance and Public Administration was created the Commission for the Reform of Public Administration (CORA). CORA's role is to propose the necessary reforms in the public administration area that would lead to higher efficiency in delivering public services and support economic growth. Red SARA connects 16 ministries, 17 autonomous communities, 2 autonomous cities and over 3708 local entities (European Commission, 2016).

Some of the first services that have been deployed through SARA are @Firma, the Public Administration Certificate Verification Platform and e-notifications that allows the Tax Agency to send notifications to businesses. The number of compulsory notifications sent to business owners has decreased tenfold since the system was introduced. @Firma provides free eID and electronic signature services to eGovernment applications. It is used to check qualified certificates and electronic signatures of both citizens and businesses. In November 2014 the Spanish Government initiated the deployment of the Cl@ve. This system unifies the access of citizens to multiple public services from access to the Spanish Tax Agency, Social Security and the Ministry of Home Affairs.

United Kingdom has been a long time champion in Europe in the use of ICT to increase the efficiency of public services. The Government Cloud (G-Cloud) is a government initiative "to ease procurement of cloud services by government departments and promote government-wide adoption of cloud computing" (Microsoft, 2016). The Digital Marketplace helps public sector organizations to find cloud technology, data center provisioning, professionals and even more. The Government Secure Intranet is the private network that interconnects Government departments and agencies. The Public Services Network "connects some 600 organizations across government, including central government departments and every local authority and council across England, Scotland and Wales" (European Commission, 2015).

The progress is remarkable when considering the huge number of public services available via the Digital Marketplace ranging from tax related services, finding financing, starting a business to access to land register, report problems related to street lights, pavement or abandoned vehicles and many more. 


\section{Conclusions}

From scalability and fast deployment to improved resources usage, from economies of scale to an improved collaboration between the actors involved cloud computing has its clear benefits for both private and public sector organizations.

While private organizations are faster in adoption and monetization of new technologies and implicitly in cloud adoption public organizations are playing on a different ground dictated by generating value for the citizens and businesses and a much more restrictive legislation. To surmount this, the first step performed in all countries had been to build and align the national legislation with the European one with respect to privacy and protection of individuals' information.

More than that data stored and transported across the systems should not get to third party jeopardizing the sovereignty of the state. To do this the second measure implemented in all countries had been to redesign and build a national communication infrastructure allowing some or all public organizations to exchange information and connect their services.

Hybrid cloud models are preferred as they provide a better control for public organizations to separate systems and services managing highly sensitive information from general interest services.

Interoperability level and defining appropriate standards needed to avoid vendor lock-in is the third step and for that the public organizations from all analyzed countries had to allocate consistent resources for analysis and implementation. In some countries the approach is to partner with major technology vendors, as in United Kingdom, for both hardware and software to build an accessible ecosystem for system integrators and any player willing to develop applications for the public services market. Other countries built custom ecosystems inspired from the commercially successful models, as it is the case for the Netherlands.

The level of high availability and the regulations to be in place for a digital marketplace is another concern for any European country willing to achieve the Digital Agenda for Europe 2020 objectives.

Considering the definition of the IaaS cloud model and the European countries reports we can't say that this is certainly in place in all analyzed countries. We can however say that some of the specific elements of IaaS are in place as IaaS allows public organization and especially the central administration to better manage the costs and evaluate the scaling infrastructure needs.

While some countries were able to build a service catalogue with the digitalized public services aggregated under the same umbrella some others are still struggling with separated e-government services that do not exchange information between them which forces citizens and private organizations to access multiple websites with different electronic identities to use them.

In regard to the PaaS cloud model we can say that there are few evidences of PaaS implementation in public organizations as most e-government services are built custom with specific hardware and software prerequisites. For both IaaS and PaaS is harder to evaluate the real level of adoption in the lack of comprehensive documents probing the existence of one or the other cloud model.

What can be easier to evaluate is the existence of SaaS as it can be easily observed and used by the citizens and private organizations operating in a country. However the 
evidences show that we are still in an early stage as the development of ICT for the public sector has focused more on developing websites and applications rather than aggregate them. While this is good on the short term as it decreases the complexity and time needed by citizens and private organizations to solve their issues it is not efficient on the long run as it will make the aggregation into a single digital marketplace across Europe difficult. To avoid this scenario the actors involved might start to cooperate and promote to all parties the needs for interoperability and a larger volume of services available. Building a common open standard for interoperability across public services developed in European countries is the next logical action to be performed by the parties involved.

As some countries are ahead of the game best practices should be shared between the public organizations that are responsible with cloud computing adoption and implementation at national level.

The free offers of cloud services, the technology advancement and the increase of cloud services usage by private organizations will also force the public sector organizations to transition faster to cloud computing.

Future research studies should focus on identifying measures to reduce the gap of cloud computing adoption between the European countries and on identifying and promoting the best practices of cloud computing in private organizations.

While in an early stage standardization is very important the future evolutions should also focus on maximizing the value provided to the citizens and private organizations acting in the European space.

\section{References}

Chellappa, R.K. (1997), Intermediaries in Cloud-Computing: A New Computing Paradigm, INFORMS Annual Meeting.

Destefani Neto, M. (2014), A brief history of cloud computing. Retrieved from https://www.ibm.com/blogs/cloud-computing/2014/03/a-brief-history-of-cloudcomputing-3/.

Draoli, M. (2014), D3.2 - Public Sector Study. FP7-610650 Cloud for Europe. Retrieved from http://www.cloudforeurope.eu/documents/10179/40740/Public+sector+study/64 08e32b-dfe9-4f13-b1bc-e410ecb71323.

EAR Online, Position Paper. Doelarchitectuur Rijks Application Store(RAS). Retrieved from http://www.earonline.nl/images/earpub/1/1f/140501_Position_Paper_RAS__Definitief.pdf.

European Commission (2010), Communication from the Commission to the European Parliament, the Council, the European Economic and Social Committee and the Committee of the Regions. A Digital Agenda for Europe. Retrieved from http://eurlex.europa.eu/legal-content/EN/TXT/PDF/?uri=CELEX:52010DC0245R(01)\&From $=$ EN.

European Commission. (2012). Communication from the Commission to the European Parliament, the Council, the European Economic and Social Committee and the Committee of the Regions. Unleashing the Potential of Cloud Computing in Europe. Retrieved from http://eur-lex.europa.eu/LexUriServ/LexUriServ.do?uri=COM:2012 :0529:FIN:EN:PDF. 
European Commission. (2015). eGovernment in Romania, January 2015, Edition 12.0. Retrieved from https://joinup.ec.europa.eu/sites/default/files/egov_in_romania__january_2015_-_v.12.0_final.pdf.

European Commission. (2015). eGovernment in the United Kingdom, February 2015, Edition 17. Retrieved from https://joinup.ec.europa.eu/sites/default/files/egov_ in_united_kingdom_-_february_2015_-_v17_final.pdf.

European Commission. (2016), eGovernment in Slovakia, February 2016, Edition 18.0. Retrieved from https://ioinup.ec.europa.eu/sites/default/files/ckeditor files/files /eGovernment\%20in\%20Slovakia\%20-\%20February2016_v1_00.pdf.

European Commission (2016), eGovernment in Spain, February 2016, Edition 18.0. Retrieved from https://joinup.ec.europa.eu/sites/default/files/ckeditor_files/files /eGovernment\%20in\%20Spain\%20-\%20February\%202016\%20-\%2018_0_4_00 .pdf.

IBM Institute for Business Value (2012), The power of cloud. Retrieved from https://www.ibm.com/cloud-computing/us/en/assets/power-of-cloud-for-busmodel-innovation.pdf.

Microsoft, United Kingdom G-Cloud v6 Official. Retrieved from https://www.microsoft.com /en-us/trustcenter/Compliance/UK-G-Cloud.

National Institute of Standards and Technology, U.S. Department of Commerce (2011), The NIST Definition of Cloud Computing. Recommendations of the National Institute of Standards and Technology. Retrieved from http://nvlpubs.nist.gov/nistpubs/Legacy /SP/nistspecialpublication800-145.pdf.

Tweneboah-Koduah, S., Endicott-Popovsky, B., Tsetse, A. (2014). Barriers to Government Cloud Adoption. International Journal of Managing Information Technology 6, 3. Retrieved from http://airccse.org/journal/ijmit/papers/6314ijmit01.pdf. 